\title{
Using the grade-rating system assessing the knowledge when teaching informational and legal disciplines in universities of law enforcement agencies
}

\author{
Anatolii Nikolaevich Grigorev ${ }^{*}$, Violetta Vladimirovna Fadeeva, Arina Chermenovna \\ Kodoeva, Natalya Vitalevna Bichan, and Irina Vladimirovna Dzyadevich \\ Kaliningrad Branch of the Saint Petersburg State University University of the Russian Ministry of \\ Internal Affairs, Kaliningrad, Russia
}

\begin{abstract}
This article discusses the practical experience of using the graderating system for assessing the knowledge of cadets in educational organizations within the Ministry of Internal Affairs of Russia when using the Moodle virtual learning environment. The advantages and disadvantages of the grade-rating system are analyzed.
\end{abstract}

Keywords: grade-rating system, module-competence approach, rating

\section{Introduction}

In the Kaliningrad branch of the Saint Petersburg University of the Ministry of Internal Affairs of Russia, the grade-rating system was first implemented to assess and register the students' progress in information and legal disciplines in the 2013-2014 academic year. As Zenkina and Agibalova rightfully point out: “... The grade-rating system allows the teacher to objectively evaluate and reliably differentiate categories of students with different levels of academic achievements, and the category of successful students with a high level of needed training is freed from the need to pass an exam and doesn't suffer from the session stress. The grade-rating system promotes the need for systematic independent activity among students in academic and extracurricular time, activating interest in searching for new solutions and developing scientific and creative activity (creative competence)" [2].

However, this system has its disadvantages, the bulkiness of traditional paper accounting records, in particular. These circumstances forced the transition from an "analog" graderating system for assessing and accounting students" progress to a "digital" one, and to the implementation of appropriate software platforms.

\section{Methods}

It is quite obvious that the implementation of the abovementioned is possible in two ways: 1) development of a custom-built automated grade-rating system; 2) use of ready-made

*Corresponding author: a.n.grigoriev@live.ru 
solutions that have already proved themselves in the educational environments of other organizations.

The undisputed leader in this class of software is Moodle (Modular Object-Oriented Dynamic Learning Environment), which allows anyone to organize and manage distance learning. On the basis of this platform, the St. Petersburg University of the Ministry of Internal Affairs of Russia deployed its distance learning system. Within this framework, the Kaliningrad branch in 2020 created an electronic course in information and legal disciplines. This course integrates a variety of educational content and various control measures within the framework of full-time distance learning, as well as the organization of a grade-rating system for evaluating and recording the cadets' and trainees' performance. The general algorithm of how the grade-rating system of assessment and accounting of students' progress works can be presented as shown in Figure 1.

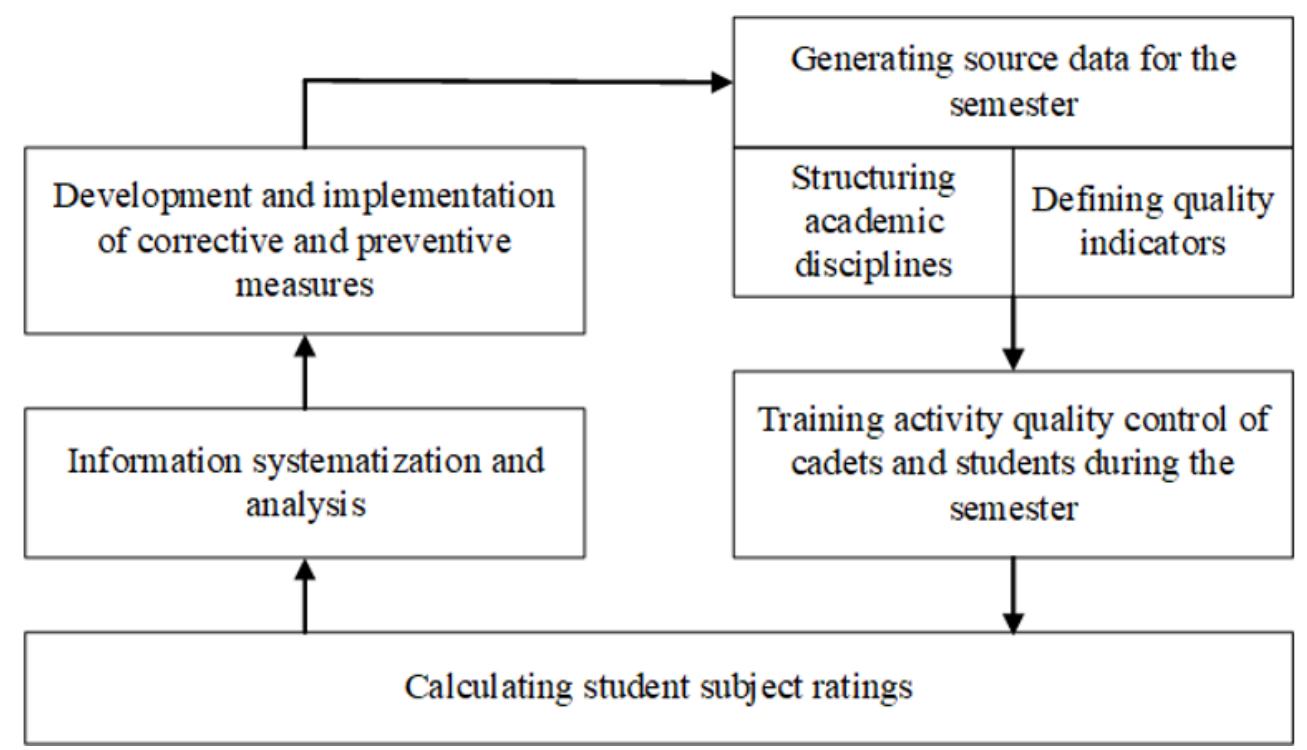

Fig. 1. The general algorithm of how the grade-rating system of assessment and accounting of students' progress works.

Before considering the mechanism for implementing a rating assessment, it is necessary to define some concepts.

Rating is a certain numerical value, an individual cumulative assessment of not only the quality of students' knowledge, expressed in a multi-grade system but also their participation in the educational process [4].

Knowledge needs to be evaluated, and knowledge-evaluation is a necessary component of the educational process. As for modular training, it is necessary to use cutting-edge new systems, and such a system is already in use.

Institutions that provide higher education in Russia widely use this system in educational practice, and, according to some authors, its use is popular "... largely due to the fact that the previously existing knowledge assessment systems gradually came into conflict with modern requirements for training qualified experts. The classical form of the exam is often ineffective because of the yearly increasing volume of information needed to be acquired. It is impossible for teachers to check every student for relevant knowledge in every course topic 
during just one exam session. In the end, students who study regularly and those who prepare from time to time and during the session time only are averaged" [4].

This system is characterized by the method of calculating ratings and types of assessment. Grades are received within a specific time period: $1 / 2$ semester of the academic year (midterm assessment), $1 / 2$ academic year (pass), academic year (final assessment at the end of the year); additional written tests, essays, and other types of assessment work completed during the academic year. Training stages (periods) are fixed points that determine the type of rating. The student achieves certain results at a certain stage. The evaluation of these results takes place either in grades or in points. This system collects the data that was determined by the final assessment, the midterm assessment, and the current assessment. All received score points (grades) are summed up by the system and the sum here represents an individual integral index. The main goal for the student is to get the maximum number of points. The role and importance of current and midpoint assessment increase rapidly when using the rating system. This trend is due to the fact that these types of assessments give the highest number of points(grades). Usually, the student's academic work takes $70-80 \%$ and the remaining $20-30 \%$ are points that the student scores on the exam. The value and significance of the system are in the ability to stimulate students to work daily and systematically. So, the grade-rating system of knowledge assessment has its advantages. First of all, the assessment of student's achievements is unbiased and tends to increase, a more accurate assessment of the study quality. The student, having the necessity to achieve a certain number of points, has the opportunity to be freed from passing the exam (test).

The standard rating for a specific discipline is defined as the maximum possible set of points that the student has the opportunity to score for the full period of studying the discipline;

The actual rating is the set of points that the student gains based on the results of all assessment activities.

The standard rating of the discipline $\mathrm{R}_{\text {norm }}$ equals 100 points and is generally determined by the formula:

$\mathrm{R}_{\text {norm }}=\mathrm{R}_{\mathrm{rub}}+\mathrm{R}_{\mathrm{ac}}+\mathrm{R}_{\text {itog }}+\mathrm{R}_{\mathrm{vk}}$,

where $\mathrm{R}_{\text {rub }}$ is the midterm assessment rating in the discipline;

$\mathrm{R}_{\mathrm{ac}}$ - instructor-led assessment rating by discipline;

$\mathrm{R}_{\text {itog }}$ is the final assessment rating in the discipline;

$\mathrm{R}_{\mathrm{vk}}$ - extracurricular assessment rating by discipline.

\section{Results and discussion}

\subsection{The midterm assessment}

The midterm assessment is carried out to determine the quality of mastering the educational material within a separate part of the academic discipline (section, block of topics, module, topic). In this regard, it seems appropriate to move to a modular content structure of academic disciplines taught in educational organizations of the Ministry of Internal Affairs of Russia, since, as L.S. Makarova notes quite correctly: “... the module organically fits into the modulerating training system, which is actively used in Russian universities... In this sense, the module, which is a logically complete part of the academic discipline, receives a grade "at the exit", and the grade, in turn, determines the student's rating. This approach provides an increase in motivation for success in mastering educational information. At the same time, the assessment and evaluation component makes it possible to systematically diagnose and correct the educational process" [2]. 


\subsection{The instructor-led assessment}

The instructor-led assessment was carried out during all training sessions in the process of mastering each topic studied. The purpose of the current assessment is a continuous analysis of the knowledge and skills assimilation level in the instructor-led forms of training - that is, during the lectures led by an instructor (or teacher), seminars, and practical classes.

Extracurricular assessment includes academic work and research conducted by students in the discipline and performed during the extracurricular time spent on the assignment and with the methodological guidance offered by the instructor/teacher, but without his direct participation. Independent work can be very diverse in terms of its form. Students can conduct research connected to the subject, they can prepare reports, library-research papers, etc.

\subsection{The final assessment}

The final assessment is an exam or test in a discipline established by the curriculum. The final assessment based on the results of mastering the discipline is formed automatically by the system which calculates points for every type of assessment involved. The compliance of the one-hundred-point rating scale used in the Moodle system with the traditional Russian five-point rating scale was established in accordance with the table below (Table 1).

Table 1. Rules for establishing the conformity of assessment scales.

\begin{tabular}{|c|c|c|c|}
\hline Rating score range & Score & Traditional rating scale & Passed / Didn't pass \\
\hline $95-100$ & 5 & \multirow{2}{*}{ Excellent } & \multirow{10}{*}{ Pass } \\
\hline $90-94$ & 4.67 & & \\
\hline $85-89$ & 4.33 & \multirow{3}{*}{ Good } & \\
\hline $80-84$ & 3.67 & & \\
\hline $75-79$ & 3.33 & & \\
\hline $70-74$ & 3 & \multirow{5}{*}{ Satisfactory } & \\
\hline $65-69$ & 2.67 & & \\
\hline $60-64$ & 2.33 & & \\
\hline $55-59$ & 1.67 & & \\
\hline $50-54$ & 1 & & \\
\hline $45-49$ & 0 & Unsatisfactory & Didn't pass \\
\hline
\end{tabular}

Thus, in order to earn the rating for a specific discipline, the student must pass all the assessment measures set by the instructor. The actual rating for the discipline is accumulated by summing up the rating indicators for all the assessment types involved. At its core, the actual rating for the discipline is an integral indicator formed on the basis of the knowledge assessment of the cadet (student) during training and based on the results of the tests and examination assessments.

Practical results for the grade-rating system usage in the educational process within the Kaliningrad Branch of the Staint Petersburg University of the Ministry of Internal Affairs of Russia in 2019-2020 academic year and in the first half of the 2020-2021 academic year can be presented with diagrams on the example of the "Computer Science and Information 
Technologies in professional activity" academic discipline taught in the first year of full-time education.

The first diagram illustrates the comparison between the final rating score for the discipline and the score received by the cadets on the exam.

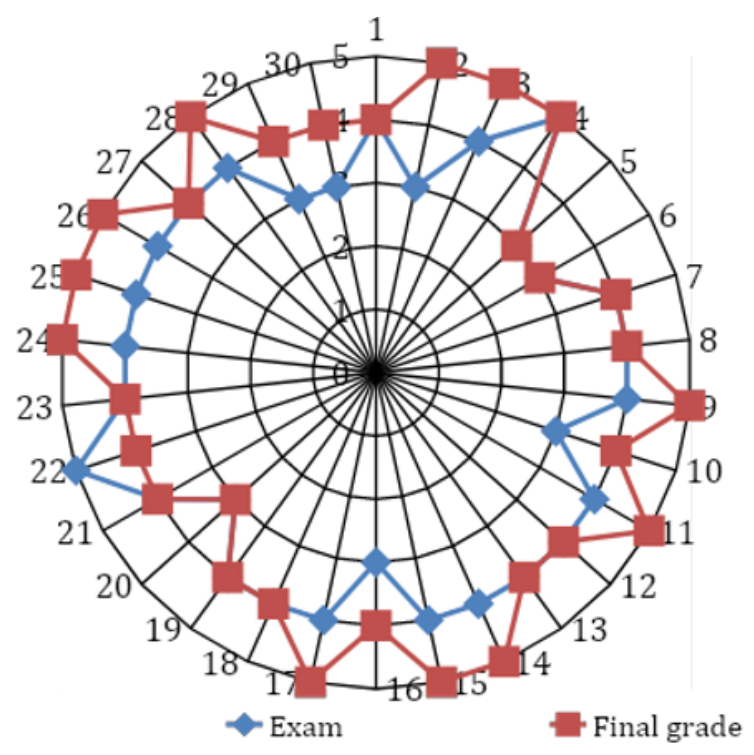

Fig. 2. The final assessment of the Computer Science and Information Technology discipline in Professional Activities discipline in comparison to the assessment cadets received during the exam.

At first glance, the ratio is not quite uniform. In a significant number of cases, the mark that the cadet received during the exam and the final mark for the discipline do not coincide. However, it seems that this circumstance can be explained logically using the following explanations:

- it is not always possible for a cadet to reveal his objective potential during the exam due to a variety of circumstances. The exam score is somewhat random in nature;

- the final assessment is an integrated result of the cadet's work during the entire study period, and the exam assessment is only one of the elements of the assessment system. There were situations when a cadet, having excellent and good grades in all stages of the midterm assessment and a high rating in the instructor-led assessment, received a satisfactory grade on the exam. It seems that every teacher has repeatedly encountered these situations.

In this regard, the authors consider more indicative another diagram illustrating the comparison of the final assessment for the specific discipline with the rating assessment of the audit control. 


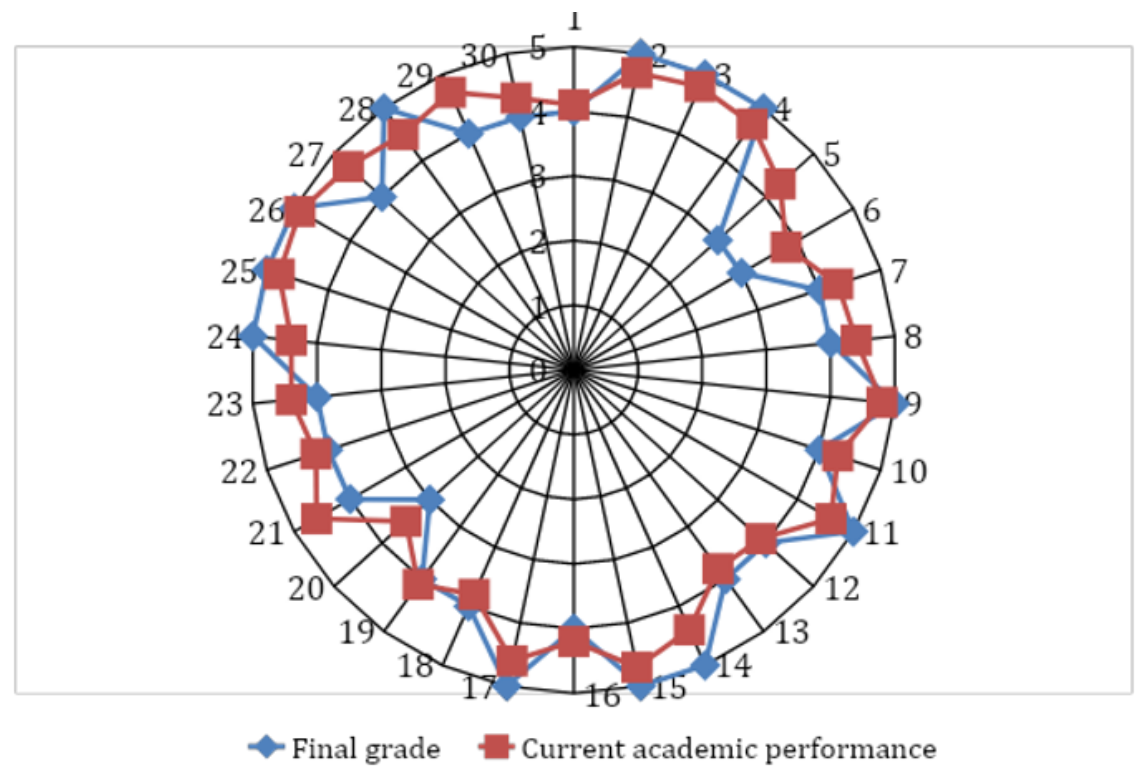

Fig. 3. The final assessment of the discipline "Computer Science and Information Technology in Professional Activities" in comparison with the rating evaluation of the instructor-led assessment.

The final assessment and the rating evaluation in the instructor-led assessment are almost identical. In some cases, the final score was even lower. To a large extent, it was due to the lack of cadets' activity within the framework of independent work.

Thus, the authors believe that the grade-rating system for assessing students' knowledge is an effective mechanism for monitoring the quality of the educational process. One of the undoubted advantages of this system is the provision of a comprehensive and objective assessment of the educational work of cadets and trainees. As for the disadvantages: the increase in the work volume for the teaching staff on the development and verification of control tasks in the electronic educational environment; the complexity of the organization of control and accounting for the students' working out of missed classes.

\section{References}

1. A.N. Grigorev, Sistema nepreryvnoi professional'noi podgotovki kadrov MVD Rossii: osnovnye problemy i perspektivy [System of continuous professional personnel training of the Ministry of Internal Affairs of Russia: main problems and prospects], in E.A. Levanova (ed.), Problemy pedagogicheskogo obrazovaniya [Problems of Pedagogical Education, vol. 41] (MPGU-MOSPI Publ., Moscow, 2013)

2. V.G. Zenkina, A.A. Agibalova, International Journal of Applied and Fundamental Research 4, 818 (2016)

3. L.S. Makarova, The Bulletin of the Adyghe State University, Series "Philology and the Arts" 4, 46 (2011)

4. A.G. Moskovkina, M.S. Valdes Odriosola, Prepodavatel XXI vek, 2(1), 198 (2016)

5. M.V. Barzhanova, Etnosocium (Multinational Society) 86(8), 70 (2015)

6. H.T. Graham, R. Bennett, Human Resource Management, transl. from Eng. (UNITYDANA Publ., Moscow, 2013) 